\title{
Nursing home residents' ADL status, institution-dwelling and association with outdoor activity: a cross-sectional study
}

\author{
Anne Marie Sandvoll ${ }^{\text {Corresp., }}$, Ellen Karine Grov ${ }^{2}$, Morten Simonsen ${ }^{3}$ \\ 1 Department of health and caring sciences, Western Norway University of Applied Sciences, Førde, Norway \\ ${ }^{2}$ Faculty of Health Sciences, Department of nursing and health promotion, Oslo Metropolitan University, Oslo, Norway \\ 3 Department of Environmental Sciences, Western Norway University of Applied Sciences, Sogndal, Norway \\ Corresponding Author: Anne Marie Sandvoll \\ Email address: annemsa@hvl.no
}

Introduction. The Norwegian regulations for nursing homes consider access to meaningful activities to be an indicator for the quality of nursing homes. Activities of daily living (ADL) provide important basic self-care skills for nursing home residents. Due to the physical changes caused by ageing and comorbidities, nursing home residents may experience functional decline over time, which may affect their ability to perform meaningful ADL, such as outdoor activity, which is considered a valuable and meaningful activity in Norwegian culture. This study aimed to investigate the association between ADL status, institution-dwelling and outdoor activity among nursing home residents.

Methods. This cross-sectional study included 784 residents aged $>67$ years living in 21 nursing homes in 15 Norwegian municipalities between November 2016 and May 2018. The Barthel Index was used to assess the nursing home residents' ADL status. Other variables collected were age, gender, body weight and height, visits per month, institution, ward, and participation in weekly outdoor activities. Descriptive statistics were used to provide an overview of the residents' characteristics. A Poisson regression model was used to test the association between the outdoor activity level as the dependent variable and ADL score, institution, and other control variables as independent variables.

Results. More than half (57\%) of the nursing home residents in this sample did not go outdoors. More than $50 \%$ of the residents had an ADL score $<10$, which indicates low performance status. Further, we found that residents' ADL status, institution, ward, and number of visits had an impact on how often the residents went outdoors.

Discussion. The nursing home residents in this study rarely went outdoors, which is interesting because Norwegians appreciate this activity. Differences in the number of visits might explain why some residents went outdoors more often than other residents did. Our findings also highlight that the institutions impact the outdoor activity. How the institutions are organized and how important this activity is considered to be in the institutions determine how often the activity is performed.

Conclusion. The low frequency of the outdoor activities might be explained by a low ADL score. More than $50 \%$ of the residents had an ADL score $<10$, which indicates low performance status. Despite regulations for nursing home quality in Norway, this result suggests that organizational differences matter, which is an important implication for further research, health policy and practice. 


\section{Nursing home residents' ADL status, institution- \\ 2 dwelling and association with outdoor activity: a \\ 3 cross-sectional study}

4 Anne Marie Sandvoll ${ }^{1}$ Ellen Karine Grov ${ }^{2}$ Morten Simonsen ${ }^{3}$

5

6

7

8

9

10

11

\footnotetext{
${ }^{1}$ Assosiate Professor, Department of health and caring sciences, Western University of Applied Sciences, Førde, Norway

${ }^{2}$ Professor, Department of nursing and health promotion, Faculty of Health Sciences, Oslo Metropolitan University, Oslo, Norway

${ }^{3}$ Assosiate Professor, Department of Enviromental Sciences, Western University of Applied Sciences, Sogndal, Norway

Corresponding author:

Anne Marie Sandvoll, Western University of Applied Sciences, P.O.Box 523, 6803 Førde, Noway

Email: annemsa@hvl.no
} 


\section{ABSTRACT}

13 Introduction. The Norwegian regulations for nursing homes consider access to meaningful activities to be an indicator for the quality of nursing homes. Activities of daily living (ADL) provide important basic self-care skills for nursing home residents. Due to the physical changes caused by ageing and comorbidities, nursing home residents may experience functional decline over time, which may affect their ability to perform meaningful ADL, such as outdoor activity, which is considered a valuable and meaningful activity in Norwegian culture. This study aimed to investigate the association between ADL status, institution-dwelling and outdoor activity among nursing home residents.

Methods. This cross-sectional study included 784 residents aged $>67$ years living in 21 nursing homes in 15 Norwegian municipalities between November 2016 and May 2018. The Barthel Index was used to assess the nursing home residents' ADL status. Other variables collected were age, gender, body weight and height, visits per month, institution, ward, and participation in weekly outdoor activities. Descriptive statistics were used to provide an overview of the residents' characteristics. A Poisson regression model was used to test the association between the outdoor activity level as the dependent variable and ADL score, institution, and other control variables as independent variables.

Results. More than half (57\%) of the nursing home residents in this sample did not go outdoors. More than $50 \%$ of the residents had an ADL score $<10$, which indicates low performance status. Further, we found that residents' ADL status, institution, ward, and number of visits had an impact on how often the residents went outdoors.

33 Discussion. The nursing home residents in this study rarely went outdoors, which is interesting because Norwegians appreciate this activity. Differences in the number of visits might explain why some residents went outdoors more often than other residents did. Our findings also highlight that the institutions impact the outdoor activity. How the institutions are organized and how important this activity is considered to be in the institutions determine how often the activity is performed.

Conclusion. The low frequency of the outdoor activities might be explained by a low ADL score. More than $50 \%$ of the residents had an ADL score $<10$, which indicates low performance status. Despite regulations for nursing home quality in Norway, this result suggests that 
42 organizational differences matter, which is an important implication for further research, health 43 policy and practice. 


\section{Introduction}

46 Norway is an example of the Nordic welfare model and its welfare state is characterized by

47 public funding and service provision (Esping-Andersen et al. 2002). Norwegian nursing homes are publicly financed, and the municipalities are responsible for providing this service. Access to meaningful activities is a reference for the quality of nursing homes as highlighted in Norwegian regulations for nursing homes (Forskr kvalitet i pleie- og omsorgstjenestene 2003). This regulation, with its specific recommendations, can be used as an indicator to assess the quality of care in nursing homes (Kirkevold \& Engedal 2006). The regulations require the municipalities to ensure that each resident is offered varied and customised activities in line with other fundamentals of care (Forskr kvalitet i pleie- og omsorgstjenestene 2003).

The availability of activities for nursing home residents may contribute to their well-being and dignity (Björk et al. 2017; Lampinen et al. 2006b; Slettebø et al. 2016). By contrast, according to Nåden et al. (2013), the lack of participation in activities in nursing homes may be explained by the residents' physical impairments, e.g., some residents need to use wheelchairs. Up to $80 \%$ of nursing home residents experience cognitive impairment (Selbaek et al. 2007), which may also limit their ability to participate in activities such as playing cards, bingo and reading groups 61 (Strøm et al. 2016).

The outdoor lifestyle traditionally holds a prominent position in Norwegian culture (Gurholt \& Broch 2019) and is considered as a valuable and meaningful activity. Unfortunately, recent inspections undertaken by the authorities in nursing homes in Norway show a lack of activity offerings (Helsetilsynet 2018a; Helsetilsynet 2018b; Helsetilsynet 2018c). The limited activity options indicate that the government's current policy and new regulations to increase the level of activities in Norwegian nursing homes have not yet succeeded (Helsetilsynet 2018a; Kjøs \& Havig 2016; Sandvoll et al. 2020; Sandvoll et al. 2012).

Despite the new regulations, changing nursing home practices is difficult (Sandvoll et al. 2012). According to Palacios-Cena et al. (2015), nursing homes should strive to develop meaningful activities for residents to occupy their time and to provide residents with a meaningful sense of purpose. However, low levels of activities of daily living (ADL) among the residents can affect their ability to participate in activities (Bürge et al. 2012). ADL are an important basic self-care skill for the general population as well as for nursing home residents. 
76 may experience functional decline over time (Drageset et al. 2011; Liu et al. 2015). Reduced

77 ADL status may impair the ability to perform activities and can impact quality of life, social

78 contact and loneliness (Liu et al. 2014b).

Physical activity, rehabilitation or exercise may improve independence and prevent the decline in ADL in elderly residents in long-term care facilities (Bürge et al. 2012; Crocker et al. 2013; Liu et al. 2014b). It is unclear which interventions are most appropriate for slowing the decline in ADL (Crocker et al. 2013), but it has been suggested that health professionals should promote physical activities with the aim of improving ADL performance among older adults (Bürge et al. 2012). The loss of ADL independence is the strongest predictor of the need for institutionalization of the elderly (Gaugler et al. 2007).

Several factors might influence nursing home residents' ADL status. Previous research has investigated the importance of ADL related to different aspects, such as loneliness, less participation in activities and depression. (Drageset 2004) has shown that dependence in ADL status is associated with a high level of social loneliness. (Drageset et al. 2011) later showed that greater dependence in ADL was associated with more symptoms of depression. Poor balance, incontinence, impaired cognition, low body mass index (BMI), impaired vision, no daily contact with proxies, impaired hearing and the presence of depression were significant risk factors for nursing home residents who experienced a decline in ADL status (Bürge et al. 2012).

Few studies have focused on the relationships between ADL status and participation in different activities among nursing home residents. One study investigated physical and social aspects of residents' mobility level and reported that nursing home residents dependent on a wheelchair or elevator during care were less involved in physical and social activities compared with more-mobile residents (Kjøs \& Havig 2016). This study suggests that reduced mobility might influence participation in different activities offered in the nursing homes. The need for activities and engagement in nursing home residents is well known (Björk et al. 2017; Kjøs \& Havig 2016; Lampinen et al. 2006a; Palacios-Ceña et al. 2015; Theurer et al. 2015). More research is needed on residents' ADL status and its relationship with participation in different activities, such as going outdoors.

Despite Norwegian regulations (Forskr kvalitet i pleie- og omsorgstjenestene 2003), the frequency and content of activities are very much up to each nursing home. Previous studies have shown differences between privately owned and government-owned facilities (Liu et al. 
107 2014a). Furthermore, previous studies have shown variations in practice regarding activities in

108 Norwegian nursing homes (Isaksen et al. 2018). To the best of our knowledge, however, little is

109 known on differences between institutions regarding their outdoor activities.

110 The aim of this study was to investigate the association between nursing home residents ADL

111 status, institution-dwelling and outdoor activity. The following research question was

112 formulated: To what extent are nursing home residents' ADL status and the institution they live

113 in associated with outdoor activity?

\section{Methods}

115 A cross-sectional design was used.

\section{Setting}

117 The data were collected by first-year nursing students during their placement in nursing homes

118 between November 2016 and May 2018. The placement was either during the autumn semester,

119 i.e., 8 weeks from the middle of October until the middle of December, or 8 weeks during the

120 spring semester, from the middle of April until the middle of June. The data were collected

121 during the daytime by means of a study manual, which the students had been presented in

122 lectures at the university. For standardized instruments and questionnaires, we used the

123 connected manual, procedure or protocol. The process of data collection was supervised by the

124 university teacher and the nurses working at the different nursing homes. Each patient was

125 registered once.

126 Our responses were collected from 21 different nursing homes. These institutions differ

127 because they have different combinations of ward types and may have different attitudes towards

128 outdoor activity. All nursing homes in this study except for one are financed and operated by the

129 municipality. The single private nursing home is not run by a commercial actor, but by the parish

130 associated with the Bergen Cathedral in Bergen, the second largest city and municipality in

131 Norway. Nursing homes all share the same national financing system.

132

133

\section{Participants}

134 The study included 784 residents aged $>67$ years living in 21 nursing homes in 15 Norwegian

135 municipalities. The inclusion criteria were all residents aged $>67$ years living in the selected 
136 nursing homes, while the exclusion criteria were residents receiving palliative care, related to

137 ethical considerations, to protect them from harm related to the completion of questionnaires in

138 their presence. In addition, residents in the palliative phase may be unable to take part in the

139 outdoor activities described in this paper. Five of the nursing homes were located in rural areas,

140 while others were located in small villages. The nursing homes were not selected completely at

141 random because the selection was partially determined by what nursing homes the nursing

142 students attended during their practice period.

144 Variables

145 We expected increasing levels of outdoor activities, e.g., making trips outside the nursing home, 146 with increasing $A D L$ score because ADL is a measurement of physical capability (higher scores

147 mean better capabilities).We observed the residents by using the method described in the Barthel

148 Index for measuring performance in ADL, as translated and revised by Saltvedt et al. (2008).

149 Each performance item is rated on this scale with a given number of points assigned to each

150 level, related to how dependent or independent the resident is, with maximum of 20 points $(20=$

151 totally dependent). The Barthel Index is a standardized, validated and psychometric-tested

152 instrument widely used in the context of elderly care (Liu et al. 2015; Mahoney \& Barthel 1965).

153 Outdoor activity is the dependent variable in our analysis. In this study, the residents either

154 walked on their own or with assistance from staff or visitors. Some residents went outdoors with

155 a walker or in a wheelchair. Some of the residents had an electric wheelchair and went outside on

156 their own. However, the purpose was still the same: outdoor activity. The level of this activity

157 was measured and documented as the number of times the activity was performed during a week.

158 Further, we introduce nursing homes as random effects to allow for the fact that not all types of

159 nursing homes are included. These effects will tell us whether activity levels vary between

160 institutions. We included a dummy variable for residing in a short-term/rehabilitation ward and

161 one for residing in a dementia ward. Long-term ward residents are expected to be older, frailer

162 and in need of more care; thus, we expected these residents to have the lowest levels of making 163 trips outside the nursing home.

164 The number of visits (per week) is interpreted as a proxy for less social isolation (Drageset 165 2004). We expected that more visits would lead to higher levels of outdoor activities. More visits 166 may also mean that relatives engage in this activity, which increases the level of ADL. 
167 Further, we expected decreasing levels of activity with increasing age (Feng et al. 2017).

168 The gender dummy variable was coded as 1 for men and 0 for women. We had no specific

169

170

171

172

173

174

175

176

177

178

179

180

181

182

183

184

185

186

187

188

189

190

191

192

193

194

195

196

expectations for a gender effect on making trips outside the nursing home.

$B M I$ is an indication of the general health condition. A low BMI indicates that residents are not eating enough (or that they fail to maintain their body weight). We expected that low BMI would be associated with fewer trips outside the nursing home.

All variables were registered in a form and documented in Excel version 16.16.19 (Microsoft, Redmond, WA, USA).

\section{Bias}

There are some limitations in using this approach. The sample is not completely randomized since the nursing homes were not selected at random, neither were the residents in the nursing homes. The students may also understand the concept differently or they did not apply it consistently. However, a detailed protocol was provided to the students so that their observations were made consistently. For instance, what date format should be used, and age and length of stay should be integer numbers. We could not eliminate ambivalence in the data collection completely.

\section{Statistical methods}

Descriptive statistics were used to give an overview of the demographic and clinical characteristics of the participants, including age, gender, BMI, ADL status, institution and the prevalence of residents' outdoor activities. We sorted the informants into different groups according to the quartiles from the distribution of ADL scores. We then analysed the levels of the outdoor activities between these groups. To further examine the association between ADL score and outdoor activity, we included age, BMI, gender, visits per month, type of ward and ADL score as well as institutions in a multivariate Poisson regression model. The data were analysed using the SAS GLIMMIX procedure with a Poisson log-link function. The two-sided significance level was set to 0.05 .

We designed a model with outdoor activity as the dependent variable and ADL status as an explanatory variable affecting the level of this activity. In addition, we controlled for several other explanatory variables that may have an influence on both activity level and ADL scores, 
197 thereby eliminating possible spurious factors. We also included institutions as an independent

198 variable, assuming they are random effects, which allows the coefficients to vary between 199 institutions.

200 We assume that institutions (nursing homes) represent several unmeasured characteristics that vary between them. These characteristics may be different service quality, different organizations, different informal routines established among staff, different efficiency in using resources, or different resident characteristics. These characteristics are not measured and probably cannot be measured. Institutions are clusters therefore we include them as random effects in the regression model to account for these variations. On the other hand, the impacts of different ward types are fixed effects since ward types have the same definition for all nursing homes and therefore do not measure any latent characteristics. The model is estimated as random intercept model, each institution has an individual- specific random effect in addition to the fixed effects of all other independent variables (SAS Institute 2019). A mixed model with both fixed and random effects that is designed to capture variations between clusters is called a conditional model (Muff et al. 2016).

212 The model allowed us to control for other regressors when assessing the effect of ADL score 213 or institutions on outdoor activity. Thus, we could compare activity level between residents in 214 the same ward and with the same age, gender, number of visits per month and BMI, but with 215 different ADL scores in different institutions.

216 Clustering occurs when entities are distributed on several levels. When this is the case, error 217 terms within a cluster will not be independently distributed of error terms in another cluster

218 (Trutschel et al. 2017). In our design, this means that error terms between nursing homes will be

219 biased if they are not accounted for in the regression model. We have already considered 220 different ward types because the chance of a resident performing the activity may be affected by 221 the ward type in which the resident lives. Nursing homes (institutions) and ward types are two 222 cluster types; therefore, we should also consider differences between nursing homes in the 223 regression model.

The table A1 (appendix A) shows the goodness-of-fit values for the regression model with trips outside the nursing home in the preceding week as the dependent variable. The dispersion criteria $\chi^{2} / \mathrm{df}$ has a value $<2$. Therefore, we assumed no overdispersion in the model. 
Further, we computed the intraclass correlation (ICC1) from the estimated model. This was

229

230

231

232

233

234

235

236

237

238

239

240

241

242

243

244

245

246

247

248

249

250

251

252

253

254

255

256

performed by using a function in R, since SAS does not provide this statistic (Lüdecke 2020a).

The correlation is calculated as the random effect variance divided by the sum of this variance

plus the residual variance. The conditional ICC1 takes the fixed effects into consideration as well as the random effects (Lüdecke 2020b). The estimated conditional ICC1 is 0,145 which means the cluster effects account for almost $15 \%$ of the variation in dependent variable making trips outdoors. The model estimated in $\mathrm{R}$ (function glmer) gives the same results as with the GLIMMIX procedure in SAS using the Laplace maximum likelihood method.

Except for the ICC1, all statistical analyses were performed using SAS software (University Edition; SAS Institute, Cary, NC, USA).

\section{Ethics}

The Regional Medical Ethics Committee (REK West), University of Bergen (2015/2030 REK WEST, University of Bergen) and the Norwegian Social Science Data Services (46303) approved the study, which was endorsed by all nursing homes. Voluntary, written informed consent was obtained from all participants. In situations where the resident was not able to give consent related to e.g., dementia or cognitive impairment, either the resident's relatives or the department manager gave consent.

\section{Results}

The sample $(n=784)$, included more women $(69 \%)$ than men $(31 \%)$, which is consistent with the population distribution in this age group (Statistisk Sentralbyrå 2016). Most residents in our sample (55\%) resided in a long-term facility, 26\% resided in a dementia ward and 19\% resided in a short-term ward. The mean ADL score was 10.1. We distributed residents into groups according to their ADL score using the quartiles from the ADL distribution, which resulted in about the same number of residents in each group. Twenty-eight per cent of the residents had an ADL score of 0-6 points as measured by the Barthel Index, 24\% had an ADL score of 7-10 points, 26\% had an ADL score of 11-14 points and 23\% had an ADL score $>15$ points.

Table 1 shows descriptive statistics for the dependent variable, trip outdoors last week. Table 2 shows descriptive statistics for the continuous independent variables while Table 3 shows descriptive statistics for categorical independent variables. 
257

258

259

260

261

262

263

264

265

266

267

268

269

270

271

272

273

274

275

276

277

278

279

280

281

282

283

284

285

Nursing homes are used as cluster variables for estimating random effects. The range is from 5 to 123 registrations per nursing home. The average was 37 registrations while the standard deviation was 31 , suggesting high variation in registrations. The nursing homes also vary considerably in size which explains some, but not all of this variation

Table 4 show the results of the model estimation with outdoor activities in the preceding week as the dependent variable. The table shows the fixed effects in the model. The random effects are available in appendix B (table A2). These are obtained by using a random intercept model, one for each nursing home, which implies that the fixed effects are assumed to be constant over all nursing homes. Long-term ward type is the reference case for ward types and its effect is measured by the model's general intercept.

The ADL score has a significant impact on the activity. An increase in the ADL score of 1 was expected to give an increase in the rate of activity level of 1.05 . We show this effect by considering two residents, both women aged 85 years, living in a long-term ward, receiving 6 visits per month and having a BMI of $23.8 \mathrm{~kg} / \mathrm{m}^{2}$ (the last two numbers are median values). Both women live in institution number 1. Resident A had an ADL score of 10, while resident B had an ADL score of 15. From our model, we expected resident A to take 0.43 trips outside the nursing home in the preceding week and resident B to take 0.56 trips. Accordingly, we expected that 16 days would be needed for resident A to take one trip outdoors and 13 days would be needed for resident $\mathrm{B}$. Had the two residents lived in institution number 7 , the expected number of trips would have been 1.3 and 1.7 trips outdoors, assuming values for age, number of visits, BMI and gender stay the same and ADL score is 10 and 15, respectively, as above. In other words, both residents $\mathrm{A}$ and $\mathrm{B}$ would have three times more outdoor activities if they had been living in institution 7 instead of 1 . This result shows that institutions have an impact on activity level. This is confirmed by estimation of institutional random effects (table A2) where eight institutions have significant effects, four of them are positive.

Table 4 also shows that age, visits per month and ward type had significant effects on the number of outdoor activities during the week. All effects were as expected: i.e., increasing age was associated with a lower activity level, whereas an increasing number of visits were associated with more trips outside the nursing home. The relative risk factor for age shows that a 
286 resident with 80 years is assumed to have 0.8 less trips outdoors previous week compared to a

287 resident with 70 years, assuming all other variables are held constant and that they reside in the

288 same institution. Also, with the same assumptions, a resident receiving 10 visits per month is

289 expected to have 1.3 more trips outdoors compared to a resident receiving only one visit per

290 month.

291 The effects of short-term wards were negative, indicating that residents in that ward type took

292 significantly fewer trips outside the nursing home than did residents in the long-term ward. On

293 the other hand, residents in dementia wards took significantly more trips outdoors than residents

294 in long-term wards. Based on the assumptions outlined above, the risk factors show that a

295 resident in the dementia ward had almost 1.6 more trips outdoors in the previous week compared

296 to a resident in the long-term ward. A resident in the short-term ward had 0.7 less trips. Gender

297 and BMI had no significant effect on the number of outdoor activities.

\section{Discussion}

299 Our findings show that institutions are important predictors for the level of trips made outdoors

300 by residents. Age and BMI index had significant effects, both negative since increasing age and

301 BMI led to fewer trips outdoors. Visits per month had a significant positive effect, more visits

302 led to more trips outdoors. In addition, ADL-score had a significant effect on the activity, the

303 lower the score, the lower the activity level.

304 Further, our findings show that $57 \%$ of the nursing home residents in this sample did not go

305 outdoors. This is consistent with other studies showing that the activities offered in nursing

306 homes are limited (Kjøs \& Havig 2016) and that the residents often are inactive (Harper Ice

307 2002). Recent inspections of nursing homes undertaken by the Norwegian authorities confirm

308 the lack of activity offerings (Helsetilsynet 2018a; Helsetilsynet 2018b; Helsetilsynet 2018c).

309 The findings of our study might be explained by the residents' ADL score, which was low:

310 i.e., $50 \%$ of the residents had an ADL score between 0 and 10. These low ADL scores indicate

311 that these residents had a low ability to go outdoors. This is consistent with national health

312 policies in Norway, which emphasize that the frailest elderly should receive care in nursing

313 homes. It is also in line with previous research that shows that the frailest residents might not be

314 able to go outdoors because of their old age, fatigue, frailty or illness (Nåden et al. 2013). 
315 However, Björk et al. (2017) performed a similar study in Sweden and reported that $60 \%$ of

316 the nursing home residents had gone outdoors during the data collection period (November

317 2013-September 2014). The differences in going outside the nursing home in these similar

318 studies from the Scandinavian health-care context are interesting. Weather and the need for

319 appropriate clothing or equipment can impede the ability of residents to go outdoors. If Björk et

320 al. (2017) collected data during the summer, it might explain some of these differences. Our data

321 were collected either during autumn or spring. In Norway the temperature and weather

322 conditions often are warmer and contain less rain during July and August, and the residents are

323 more likely to go outdoors. This might explain why the residents in the Swedish study went

324 outside more often (Björk et al. 2017). Further, our data were collected in the western part of

325 Norway which has more rain compared to the eastern parts of Norway where most people live.

326 In addition, these residents might not have proper clothing like raincoats, warm jackets,

327 appropriate shoes or hats suitable for the different weather conditions. The British Broadcasting

328 Corporation (BBC 2018) has shown how the use of a rickshaw with a roof and cover may be an

329 alternative for helping frail elderly people to perform outdoor activities despite their loss in ADL

330 status. The concept of outdoor life, in particular hiking, has a prominent position in the

331 Norwegian culture (Gurholt \& Broch 2019). In addition, most of the older population in Norway

332 grew up after the last world war; therefore, many have received basic socialization in outdoor life

333 and have maintained their association with outdoor activities throughout their lives (Odden

334 2008).

335 Our findings highlight that institutions have an impact on how often residents go outdoors.

336 These findings suggest that organizational differences impact outdoor activity. How the

337 institutions are organized and the importance they give this activity obviously determine how

338 often it is performed. These findings are in line with Isaksen et al. (2018), who found that only

339 four of 17 nursing homes had activity plans for the wards. Further, they found variations in staff

340 who had participated in training program regarding activities for the residents (Isaksen et al.

341 2018). Even if the service going outdoor is regulated by national regulations (Forskr kvalitet $\mathrm{i}$

342 pleie- og omsorgstjenestene 2003), there is considerable room for adaption in each nursing

343 home. The variation in service provision between nursing homes comes from different cultures,

344 organizational practices and plainly the priority the service gets when set against other services

345 the nursing homes are obliged to provide (Nakrem 2015). To increase the level of activity, 
346 students should be given more information about the benefits of the activity for nursing home

347 residents as well as the legal rights of this activity.

348 Physical activity is important for mental well-being among elderly people (Lampinen et al.

349 2006b). However, our findings show that increasing age was associated with lower activity

350 levels, which is also in line with Feng et al. (2017). This might imply a natural change from

351 being active to being less active and in need for assistance, which corresponds with the process

352 of disengagement described by Cumming and Henry in 1961 (Daatland \& Solem 2011). When

353 people get older, it is natural for them to gradually withdraw from their social roles and the

354 activities they used to perform. This is in line with Adams et al. (2011), who found that activity

355 participation in late life changed from an active social life with creative activities to an increased

356 participation in passive social and spiritual activities. Nursing homes must consider this and meet

357 their residents' individual needs and interests. According to the Norwegian quality regulations,

358 nursing home residents should be offered varied and customized activities (Forskr kvalitet $\mathrm{i}$

359 pleie- og omsorgstjenestene 2003). Nursing homes need to facilitate activities that are suitable

360 for each resident's ADL status and individual wishes. For example, it might be important for

361 residents to have their own personal things near their own chair. A nearby table might contain

362 personal important objects, such as magazines, books, newspapers or medicines (Board \&

363 McCormack 2018). Nursing home residents who are no longer capable or do not want to go

364 outside might appreciate a nice view (Eijkelenboom et al. 2017). Activities are a basic need and

365 participation in activities might contribute to the well-being and dignity experienced by nursing

366 home residents (Björk et al. 2017; Lampinen et al. 2006b; Slettebø et al. 2016). Such activities

367 should be organized by the staff in close co-operation with relatives because they are familiar

368 with the residents' needs (Sandvoll et al. 2012).

369 Previous research shows that nursing home staff are committed to routines, such as helping

370 residents with personal care, practical help, nutrition and toileting (Harnett 2010; Sandvoll et al.

371 2012), but do not always take a person-centred approach (McCormack 2016) in terms of their

372 activities. Nursing homes often lack the opportunity and time to offer activities for all residents

373 and their staff recognize that some residents may spend time sitting alone even though staff

374 members know that they might have preferred to join in activities (Sandvoll et al. 2015). Could

375 the lack of staff explain our study results? Our findings show that visits per month and ward type

376 had a significant effect on number of outdoor activities during the week. An increasing number 
377 of visits were associated with more trips outside the nursing home. This shows that the visits

378 (from family or volunteers) have an impact on resident's level of activities regarding outdoor

379 activity. In Norway, the government has addressed new ideas to solve the staff challenges and

380 suggests that voluntary contributions by relatives and organizations should be included as a way

381 of providing activities for nursing home residents (Det kongelige kulturdepartement 2018; Helse-

382 og omsorgsdepartementet 2013).

383 A reform to improve elderly care was introduced in a recent white paper from the Norwegian

384 government. One of the main areas that need improvement in elderly care is activities for elderly

385 people living in nursing homes and the white paper suggests that they should participate in one

386 hour of activity every day (Helse- og omsorgsdepartementet 2018). To provide more activities

387 for nursing home residents, particularly outdoor activities, nursing home staff should be given

388 resources to organize individual, person-centred and customized activities for all residents and to

389 co-ordinate voluntary contributions (e.g., from family members and elderly that want to

390 participate in activities). This is consistent with a recent study by Skinner et al. (2018), who

391 found that the voluntary, unpaid contribution took place within cultural, social and other

392 activities aimed at promoting mental stimulation and well-being. Furthermore, they suggested

393 that the staff in government nursing homes should consider voluntary contributions when they

394 plan the care of residents in long-term care (Skinner et al. 2018). To offer a variety of activities

395 for nursing home residents, activities should be offered both inside and outside the nursing home.

396 We also encourage the national authorities to specify in white papers that activities for

397 Norwegian nursing home residents should take place both indoors and outdoors. For residents

398 who are unable to go outdoors on their own, rickshaws might serve as an alternative way of

399 enabling them to go outdoors. Our findings show that nursing home residents rarely engage in

400 outdoor activities, even though the need for activities and engagement for nursing home residents

401 is well known internationally (Björk et al. 2017; Kjøs \& Havig 2016; Lampinen et al. 2006a;

402 Palacios-Ceña et al. 2015; Theurer et al. 2015). Therefore, a greater focus on activities for

403 elderly nursing home residents should be increased and customized in line with each resident's

404 individual needs and wishes. Finally, our results show that the institution that the residents live in

405 has an important association with outdoor activity. This implies that organizational differences in

406 nursing homes might have an impact on outdoor activity, which is an important implication for

407 further research, health policy and practice. 


\section{Strengths and weaknesses}

409 The strength of this study is the systematic use of standardized, psychometric-tested instruments

410 and measures (Mahoney \& Barthel 1965). One weakness is related to the nursing students'

411 observations used to rate ADL. One obligation of research is not to harm participations; i.e., even

412 though self-report is recommended as the gold standard for gathering data (Polit \& Beck 2017),

413 self-report was considered to be inappropriate for assessing the ADL of these residents. The

414 students' involvement in research might contribute to mutually strengthening research and

415 education. The students used a predefined manual or standardized protocol to assess data, which

416 is an advantage, particularly since the lecture was given immediately before clinical placement.

417 The data collection was supervised by the university teacher and nurses working at the different

418 nursing homes. This might, on the other side, be a bias in this study because the involvement

419 might serve as a Hawthorne effect (Polit \& Beck 2017). The participants represent a convenient

420 sample from clinical placements where the university has contracts educating students. In such a

421 way, it might be limited possibilities for generalization of the results to all nursing homes.

422

423 Conclusions

424 More than half (57\%) of the participants in this study did not go outdoors during the preceding 425 week. Their ADL status might explain this pattern because more than $50 \%$ of the residents had 426 an ADL score $<10$, which indicates low performance status. The institutions that the residents 427 live in have an impact on outdoor activity, which suggests that organizational differences matter. 428 This is an important implication for further research, health policy and practice. Planning for 429 nursing home residents' activities requires staff competence in assessing the capacity and needs 430 of all residents. Those residents with few family members or friends might benefit from visits

431 from volunteers taking on an important function in collaboration with the nursing staff in 432 managing different kind of activities, such as outdoor activities. Our findings show that residents 433 rarely engage in outdoor activities, even though the need for activities and engagement for 434 nursing home residents is well known. Therefore, a greater focus on activities for elderly nursing 435 home residents should be increased and customized in line with each resident's individual needs 436 and wishes. 


\section{References}

438 Adams KB, Roberts AR, and Cole MB. 2011. Changes in activity and interest in the third and

439

440

441

442

443

444

445

446

447

448

449

450

451

452

453

454

455

456

457

458

459

460

461

462

463

464

465

466

467

468

469

470

471

472

473

474

475

476

477

478

479

480 fourth age: associations with health, functioning and depressive symptoms.

Occupational Therapy International 18:4. https://doi.org/10.1002/oti.304

BBC. 2018. Bury St Edmunds rickshaws aim to tackle loneliness. Available at https://www.bbc.co.uk/news/av/uk-england-suffolk-44363028/bury-st-edmundsrickshaws-aim-to-tackle-loneliness.

Björk S, Lindkvist M, Wimo A, Juthberg C, Bergland Å, and Edvardsson D. 2017. Residents' engagement in everyday activities and its association with thriving in nursing homes. Journal of Advanced Nursing 73:1884. https://doi.org/10.1111/jan.13275

Board M, and McCormack B. 2018. Exploring the meaning of home and its implications for the care of older people. Journal of Clinical Nursing 27:3070-3080. https://doi.org/10.1111/jocn.14495

Bürge E, von Gunten A, and Berchtold A. 2012. Factors favoring a degradation or an improvement in activities of daily living (ADL) performance among nursing home $(\mathrm{NH})$ residents: A survival analysis. Archives of Gerontology and Geriatrics 56:250257. https://doi.org/10.1016/j.archger.2012.09.001

Crocker T, Young J, Forster A, Brown L, Ozer S, and Greenwood DC. 2013. The effect of physical rehabilitation on activities of daily living in older residents of long-term care facilities: systematic review with meta-analysis. Age and Ageing 42:682-688. 10.1093/ageing/aft133

Det kongelige kulturdepartement. 2018. Frivilligheita - sterk, sjølvstendig, mangfaldig. Den statlege frivilligheitspolitikken [Volunteering - strong, independent, diverse. The state Volunteer Policy]. Available at https://www.regjeringen.no/no/dokumenter/meld.-st.-10-20182019/id2621384/ (accessed 10th December 2019).

Drageset J. 2004. The importance of activities of daily living and social contact for loneliness: a survey among residents in nursing homes. Scandinavian Journal of Caring Sciences 18:65-71.

Drageset J, Eide GE, and Ranhoff AH. 2011. Depression is associated with poor functioning in activities of daily living among nursing home residents without cognitive impairment. Journal of Clinical Nursing 20:3111-3118. https://doi.org/10.1111/j.1365-2702.2010.03663.x

Daatland SO, and Solem PE. 2011. Aldring og samfunn : innføring i sosialgerontologi [Aging and society: introduction to social gerontology]. Bergen: Fagbokforlaget.

Eijkelenboom A, Verbeek H, Felix E, and van Hoof J. 2017. Architectural factors influencing the sense of home in nursing homes: An operationalization for practice. Frontiers of Architectural Research 6:111-122. https://doi.org/10.1016/j.foar.2017.02.004

Esping-Andersen G, Gallie D, Hemerijck A, and Myles J. 2002. Why we need a new welfare state. Oxford: Oxford University Press.

Feng Z, Lugtenberg M, Franse C, Fang X, Hu S, Jin C, and Raat H. 2017. Risk factors and protective factors associated with incident or increase of frailty among communitydwelling older adults: A systematic review of longitudinal studies.(Research Article)(Report). PLoS ONE 12:e0178383. 10.1371/journal.pone.0178383 
481 Forskr kvalitet i pleie- og omsorgstjenestene. 2003. FOR 2003-06-27 nr 792: Forskrift om

482

483

484

485

486

487

488

489

490

491

492

493

494

495

496

497

498

499

500

501

502

503

504

505

506

507

508

509

510

511

512

513

514

515

516

517

518

519

520

521

522

523

524

525

526 kvalitet i pleie- og omsorgstjenestene for tjenesteyting etter lov av 19. november $1982 \mathrm{nr} .66$ om helsetjenesten i kommunene og etter lov av 13. desember $1991 \mathrm{nr}$. 81 om sosiale tjenester m.v. [Regulations for quality of care in the municipalities]. Available at http://www.lovdata.no/cgi-wift/ldles?doc=/sf/sf/sf-20030627-0792.html (accessed 10th December 2019).

Gaugler JE, Duval S, Anderson KA, and Kane RL. 2007. Predicting nursing home admission in the U.S.: A meta-analysis. BMC Geriatrics 7. https://doi.org/10.1186/1471-23187-13

Gurholt KP, and Broch TB. 2019. Outdoor life, nature experience, and sports in Norway: tensions and dilemmas in the preservation and use of urban forest. Sport in Society 22:573-588. 10.1080/17430437.2017.1390938

Harnett T. 2010. Seeking exemptions from nursing home routines: Residents'everyday influence attempts and institutional order. Journal of Aging Studies 24:292-301. https://doi.org/10.1016/j.jaging.2010.08.001

Harper Ice G. 2002. Daily life in a nursing home: has it changed in 25 years? Journal of Aging Studies 16:345. 10.1016/S0890-4065(02)00069-5NB

Helse- og omsorgsdepartementet. 2013. Meld. St. 29 (2012-2013) Morgendagens omsorg [Tomorrow's Care]. Oslo, .

Helse- og omsorgsdepartementet. 2018. Meld. St. 15 (2017-2018) A full life - all your life A Quality Reform for Older Persons Available at https://www.regjeringen.no/en/dokumenter/meld.-st.-15-20172018/id2599850/ (accessed 10th December 2019).

Helsetilsynet. 2018a. Rapport fra tilsyn med helse- og omsorgstjenester til beboere ved Lødingen sykehjem 2018 [Report after inspection of care services for residents in Lødingen nursing home]. Available at https://www.helsetilsynet.no/tilsyn/tilsynsrapporter/nordland/2018/lodingensykehjem-helse--og-omsorgstjenester-til-beboere-2018/ (accessed 10th December 2019).

Helsetilsynet. 2018b. Rapport fra tilsyn med tjenesten til eldre med behov for heldøgns helse- og omsorgstjeneste ved Meråker helsetun, avd. sykehjemmet 2018 [Report after inspection of care services for residents in Meråker nursing home]. Available at https://www.helsetilsynet.no/tilsyn/tilsynsrapporter/trondelag/2018/meraakerhelsetun-avdeling-sykehjemmet-tjenesten-til-eldre-med-behov-for-heldogns-helse-ogomsorgstjeneste-2018/(accessed 10th December 2019).

Helsetilsynet. 2018c. Rapport fra tilsyn med tjenesten til eldre med heldøgns helse- og omsorgstjenester i Trondheim kommune, Dragvoll helse- og velferdssenter 2018 [Report after inspection of care services for residents in Trondheim municipality]. Available at https://www.helsetilsynet.no/tilsyn/tilsynsrapporter/trondelag/2018/trondheimkommune-dragvoll-helse-og-velferdssenter-tilsyn-med-tjenesten-til-eldre-medheldoegns-helse-og-omsorgstjenester-2018/ (accessed 10th December 2019).

Isaksen J, Ågotnes G, and Fagertun A. 2018. Spenningsfeltet mellom standardisering, variasjon og prioritering i norske sykehjem [Tensions Between Standardization in Norwegian Nursing Homes]. Tidsskrift for omsorgsforskning 4:143-152. 10.18261/issn.2387-5984-2018-02-10 
527

528

529

530

531

532

533

534

535

536

537

538

539

540

541

542

543

544

545

546

547

548

549

550

551

552

553

554

555

556

557

558

559

560

561

562

563

564

565

566

567

568

569

570

571

Kirkevold $\varnothing$, and Engedal K. 2006. The quality of care in Norwegian nursing homes. Scandinavian Journal of Caring Sciences 20:177-183. https://doi.org/10.1111/j.1471-6712.2006.00396.x

Kjøs BØ, and Havig AK. 2016. An examination of quality of care in Norwegian nursing homes-a change to more activities? Scandinavian Journal of Caring Sciences 30:330339. https://doi.org/10.1111/scs.12249

Lampinen P, Heikkinen R, Kauppinen M, and Heikkinen E. 2006a. Activity as a predictor of mental well-being among older adults. Aging \& Mental Health 10 454-466 https://doi.org/10.1080/13607860600640962

Lampinen P, Heikkinen RL, Kauppinen M, and E. H. 2006b. Activity as a predictor of mental well-being among older adults. Aging \& Mental Health 10:454-466. https://doi.org/10.1080/13607860600640962

Liu C, Feng Z, and Mor V. 2014a. Case-Mix and Quality Indicators in Chinese Elder Care Homes: Are There Differences Between Government-Owned and Private-Sector Facilities? Journal of the American Geriatrics Society 62:371-377. 10.1111/jgs.12647

Liu C-j, Shiroy D, Jones L, and Clark D. 2014b. Systematic review of functional training on muscle strength, physical functioning, and activities of daily living in older adults. European Review of Aging and Physical Activity 11:95-106. 10.1007/s11556-0140144-1

Liu WL, Unick JU, Galik EG, and Resnick B. 2015. Barthel Index of Activities of Daily Living. Item Response Theory Analysis of Ratings for Long-Term Care Residents. Nursing Research 64:88-99. https://doi.org/10.1097/nnr.0000000000000072

Lüdecke D. 2020a. Intraclass Correlation coefficient, R Documentation. Available at https://www.rdocumentation.org/packages/sjstats/versions/0.17.4/topics/icc.

Lüdecke D. 2020b. Package 'performance'. Available at https://cran.rproject.org/web/packages/performance/performance.pdf.

Mahoney FI, and Barthel DW. 1965. Functional evaluation: the Barthel index. Maryland State Medical Journal 14:61-65.

McCormack B. 2016. Person-Centredness and Fundamentals of Care - Dancing with Beauty Rather than Fighting Ugliness. Nursing Leadership 29:17-25. $10.12927 /$ cjnl.2016.24642

Muff S, Held L, and Keller LK. 2016. Marginal or conditional regression models for correlated non-normal data. Ecology and Evolution 7.

Nakrem S. 2015. Understanding organizational and cultural premises for quality of care in nursing homes: an ethnographic study. BMC Health Serv Res 15:508. 10.1186/s12913-015-1171-y

Nåden D, Rehnsfeldt AW, Råholm M-B, Lindwall L, Caspari S, Aasgaard T, Slettebø Å, Sæteren B, Lillestø B, Heggestad AKT, and Lohne V. 2013. Aspects of indignity in nursing home residences as experienced by family caregivers. Nursing Ethics 20:748-761. https://doi.org/10.1177/0969733012475253

Odden A. 2008. Hva skjer med norsk friluftsliv?: En studie av utviklingstrekk i norsk friluftsliv 1970-2004 [What happens to norwegian outdoor life? a study of developments in Norwegian outdoor life 1970-2004] phd. Norges teknisknaturvitenskapelige universitet, Fakultet for samfunnsvitenskap og teknologiledelse, Geografisk institutt. 
572 Palacios-Ceña D, Gómez-Calero C, Cachón-Pérez JM, Velarde-García JF, Martínez-Piedrola R, 573 and Pérez-De-Heredia M. 2015. Is the experience of meaningful activities

574

575

576

577

578

579

580

581

582

583

584

585

586

587

588

589

590

591

592

593

594

595

596

597

598

599

600

601

602

603

604

605

606

607

608

609

610

611

612

613

614

615 understood in nursing homes? A qualitative study. Geriatric Nursing 37:110-115. http://dx.doi.org/10.1016/i.gerinurse.2015.10.015

Polit DF, and Beck CT. 2017. Nursing Research : generating and assessing evidence for nursing practice. Philadelphia: Wolters Kluwer.

Saltvedt I, Helbostad JL, Sveen U, Thingstad P, Sletvold O, and Wyller TB. 2008. Barthel ADL-INDEKS Norwegian version based on Mahoney F.I. \& Barthel D.W. (1965). Available at https://aldring-og-helsemedia.s3.amazonaws.com/documents/barthel010408_2.pdf.

Sandvoll AM, Hjertenes A-M, and Board M. 2020. Perspectives on activities in nursing homes. International Practice Development Journal 10:1-12. https://doi.org/10.19043/ipdj.10Suppl.006

Sandvoll AM, Kristoffersen K, Grov EK, and Hauge S. 2015. When care situations evoke difficult emotions inn nursing staff members: an ethnographic study in two Norwegian nursing homes. BMC Nursing 14. 10.1186/s12912-015-0093-7

Sandvoll AM, Kristoffersen K, and Hauge S. 2012. New quality regulations versus established nursing home practice- a qualitative study. BMC Nursing 11:14. https://doi.org/10.1186/1472-6955-11-7

SAS Institute. 2019. Introduction to Statistical Modeling with SAS/STAT Software. SAS Institute.

Selbaek G, Kirkevold $\varnothing$, and Engedal K. 2007. The prevalence of psychiatric symptoms and behavioural disturbances and the use of psychotropic drugs in Norwegian nursing homes. International Journal Of Geriatric Pshychiatry 22:843-849.

Skinner MS, Sogstad MKR, and Tingvold L. 2018. Voluntary work in the Norwegian longterm care sector: complementing or substituting formal services? European Journal of Social Work:1-13. 10.1080/13691457.2018.1462767

Slettebø Å, Sæteren B, Caspari S, Lohne V, Rehnsfeldt AW, Heggestad AKT, Lillestø B, Høj B, Råholm M-B, Lindwall L, Aasgaard T, and Nåden D. 2016. The significance of meaningful and enjoyable activities for nursing home resident's experiences of dignity. https://doi.org/10.1111/scs.12386

Statistisk Sentralbyrå. 2016. https://www.ssb.no/befolkning. Available at https://www.ssb.no/befolkning?rn=F\&innholdstype=statistikk\&de=Befolkningsframsk rivinger\#tittel.

Strøm BS, Ytrehus S, and Grov E-K. 2016. Sensory stimulation for persons with dementia: a review of theliterature. Journal of Clinical Nursing 25:1805-1834.

Theurer K, Mortenson WB, Stone R, Suto M, Timonen V, and Rozanova J. 2015. The need for a social revolution in residential care. Journal of Aging Studies 35:201-210. 10.1016/j.jaging.2015.08.011

Trutschel D, Palm R, Holle B, and Simon M. 2017. Methodological approaches in analysing observational data: A practical example on how to address clustering and selection bias. International Journal of Nursing Studies:36-44. https://doi.org/10.1016/j.ijnurstu.2017.06.017

616 


\section{Table $\mathbf{1}$ (on next page)}

Descriptive statistics for dependent variable, trips outdoors last week

Table 1 shows descriptive statistics for the dependent variable, trip outdoors last week. 
1 Table 1 Descriptive statistics for dependent variable, trips outdoors last week

\begin{tabular}{|l|r|}
\hline \multicolumn{2}{|c|}{ Trips outdoors last week } \\
\hline Min & 0 \\
\hline $25^{\text {th }}$ percentile & 0 \\
\hline Median & 0 \\
\hline $75^{\text {th }}$ percentile & 1 \\
\hline $95^{\text {th }}$ percentile & 4 \\
\hline Max & 14 \\
\hline Number of observations & 784 \\
\hline
\end{tabular}

2 


\section{Table 2 (on next page)}

Descriptive statistics for numeric independent variables

Table 2 shows descriptive statistics for the continuous independent variables 
1 Table 2 Descriptive statistics for numeric independent variables

\begin{tabular}{|l|r|r|r|}
\hline ADL score & Mean & $\begin{array}{r}\text { Standard } \\
\text { deviation }\end{array}$ & $\begin{array}{c}\text { Number of } \\
\text { observations }\end{array}$ \\
Age & 10.1 & 5.2 & 787 \\
Visits per month & 86.3 & 7.2 & 786 \\
Body mass index & 8.9 & 8.8 & 787 \\
\hline
\end{tabular}

2 


\section{Table 3(on next page)}

Descriptive statistics for categorical variables ward type and gender used as independent variables

Table 3 shows descriptive statistics for categorical independent variables 
1 Table 3 Descriptive statistics for categorical variables ward type and gender used as 2 independent variables

\begin{tabular}{lrr} 
& N & $\begin{array}{c}\text { \% of } \\
\text { total }\end{array}$ \\
\hline \multicolumn{1}{c}{ Ward type } & & \\
\hline Short term/rehab & 153 & 19.4 \\
\hline Long term & 434 & 55.1 \\
\hline Dementia & 200 & 25.4 \\
\hline Total & 787 & 99.9 \\
\hline & Gender & \\
\hline Female & 543 & 69 \\
\hline Male & 244 & 31 \\
\hline Total & 787 & 100
\end{tabular}

3 


\section{Table 4(on next page)}

Model estimates of outdoor activities in the preceding week: Poisson regression

Table 4 show the results of the model estimation with outdoor activities in the preceding week as the dependent variable 
1 Table 4 Model estimates of outdoor activities in the preceding week: Poisson regression

\begin{tabular}{lccrrrr}
\multicolumn{1}{c}{ Effect } & Estimate & $\begin{array}{c}\text { Relative } \\
\text { risk }\end{array}$ & $\begin{array}{c}\text { Standard } \\
\text { error }\end{array}$ & df & t value & Pr $>|\mathbf{t}|$ \\
\hline Intercept & 0.925 & & 0.590 & 20 & 1.57 & 0.133 \\
\hline ADL & 0.052 & 1.054 & 0.008 & 756 & 6.72 & $<.0001$ \\
\hline Gender (1 = Male) & 0.102 & 1.107 & 0.086 & 756 & 1.18 & 0.238 \\
\hline Age & -0.024 & 0.976 & 0.006 & 756 & -4.18 & $<.0001$ \\
\hline Visit Pr month & 0.030 & 1.031 & 0.004 & 756 & 7.68 & $<.0001$ \\
\hline BMI & -0.005 & 0.995 & 0.008 & 756 & -0.60 & 0.548 \\
\hline Dementia & 0.462 & 1.588 & 0.115 & 756 & 4.00 & $<.0001$ \\
\hline Short-term & -0.309 & 0.734 & 0.135 & 756 & -2.29 & 0.023 \\
rehabilitation ward & & & & & &
\end{tabular}

AIC

1973.25

Variance random effect

0.1532 
Table 5 (on next page)

\section{Appendix A}

Table A1 Model statistics for Poisson regression model 


\section{Appendix A}

2 Table A1 Model statistics for Poisson regression model for outdoor activities in the

3 preceding week as a dependent variable

\begin{tabular}{lccc}
\hline Goodness-of-fit criteria & df & $\chi^{\mathbf{2}}$ & $\chi^{\mathbf{2} / \mathbf{d f}}$ \\
\hline Generalized chi-square & 774 & 1216.3 & 1.57 \\
Number of observations & & 784 & \\
\hline
\end{tabular}

4 
Table 6(on next page)

Appendix B

Table A2 Model estimates of outdoor activities in the preceding week - random effects 


\section{Appendix B}

2 Table A2 Model estimates of outdoor activities in the preceding week: random effects

\begin{tabular}{|l|r|r|r|r|r|}
\hline \multicolumn{1}{|c|}{ Institution } & \multicolumn{1}{c|}{ Estimate } & \multicolumn{1}{c|}{$\begin{array}{c}\text { Standard } \\
\text { Error }\end{array}$} & df & t value & Pr $>|\mathbf{t}|$ \\
\hline InstId 1 & -0.430 & 0.1896 & 756 & -2.27 & 0.0236 \\
\hline InstId 2 & 0.595 & 0.1793 & 756 & 3.32 & 0.0009 \\
\hline InstId 3 & -0.247 & 0.1671 & 756 & -1.48 & 0.139 \\
\hline InstId 4 & -0.031 & 0.2164 & 756 & -0.14 & 0.8872 \\
\hline InstId 5 & -0.140 & 0.3083 & 756 & -0.45 & 0.6499 \\
\hline InstId 6 & -0.453 & 0.2255 & 756 & -2.01 & 0.0451 \\
\hline InstId 7 & 0.689 & 0.1519 & 756 & 4.54 & $<.0001$ \\
\hline InstId 8 & -0.567 & 0.2713 & 756 & -2.09 & 0.0371 \\
\hline InstId 9 & 0.099 & 0.2133 & 756 & 0.46 & 0.6441 \\
\hline InstId 10 & -0.036 & 0.1487 & 756 & -0.24 & 0.8068 \\
\hline InstId 11 & 0.630 & 0.3366 & 756 & 1.87 & 0.0615 \\
\hline InstId 12 & 0.420 & 0.1742 & 756 & 2.41 & 0.0161 \\
\hline InstId 13 & 0.155 & 0.2227 & 756 & 0.69 & 0.4881 \\
\hline InstId 14 & -0.022 & 0.1521 & 756 & -0.14 & 0.8866 \\
\hline InstId 15 & -0.284 & 0.2389 & 756 & -1.19 & 0.2343 \\
\hline InstId 16 & 0.472 & 0.2612 & 756 & 1.81 & 0.0713 \\
\hline InstId 17 & -0.518 & 0.2509 & 756 & -2.06 & 0.0395 \\
\hline InstId 18 & 0.021 & 0.3065 & 756 & 0.07 & 0.9453 \\
\hline InstId 19 & 0.243 & 756 & 0.6 & 0.5478 \\
\hline InstId 20 & 0.3453 & 756 & -1.08 & 0.2821 \\
\hline InstId 21 & & & 756 & 0.79 & 0.4322 \\
\hline & & & & & \\
\hline
\end{tabular}

